Gênero, Saúde, Corporeidades

\title{
0 que esperam pessoas trans do Sistema Único de Saúde?
}

Pablo Cardozo Rocon ${ }^{(a)}$

Francis Sodré(b)

Jésio Zamboni ${ }^{(c)}$

Alexsandro Rodrigues $^{(\mathrm{d})}$

Maria Carolina Fonseca Barbosa Roseiro ${ }^{(e)}$

Rocon PC, Sodré F, Zamboni J, Rodrigues A, Roseiro MCFB. What trans people expect of the Brazilian National Health System?. Interface (Botucatu). 2018; 22(64):43-53.

This article discusses the criticisms and suggestions made by transgender people to guarantee their access to the public health services, and regarding the health promotion through comprehensive care actions in the Brazilian National Health System (SUS). Semi-structured interviews were conducted, recorded on digital audio, transcribed and subject to content analysis. The interviews suggested the need of lifelong education to health workers, in order to reverse the present discrimination, the disrespect regarding the social name and the difficult dialogue between professionals and transgender users hamperingaccess to public health. It is pointed out the need to universalize hormone therapy and silicone implants, and requests a multidisciplinary care to transgender health as ways to ensure the care and safety required for the body transformation processes.

Keywords: Transgender people. Acess. Health. Body. Gender. Brazilian National Health System.
Este artigo discute as críticas e sugestões apresentadas por pessoas trans para garantia de seu acesso e da promoção de ações para cuidado integral de sua saúde no Sistema Único de Saúde (SUS). Foram realizadas entrevistas semiestruturadas, gravadas em áudio, transcritas e realizada análise de conteúdo. Apontou-se a formação continuada para trabalhadores da saúde, com o objetivo de reverter a realidade de discriminação, desrespeito ao nome social e dificuldade de diálogo entre profissionais e usuários trans, condições que limitam o acesso à saúde. Considerouse a necessidade de universalizar a hormonioterapia e o implante de silicone e a reivindicação por atendimento multiprofissional na saúde trans como formas de garantir o cuidado e a segurança necessários aos processos de transformação do corpo.

Palavras-chave: Pessoas transgênero. Acesso. Saúde. Corpo. Gênero. Sistema Único de Saúde. (a,b) Programa de PósGraduação em Saúde Coletiva, Universidade Federal do Espírito Santo. Av. Fernando Ferrari, 514, Goiabeiras. Vitória, ES, Brasil. 29075-910. pablocardoz@ gmail.com; francisodre@uol.com.br

$(c, d, e)$ Programa de Pós-Graduação em Psicologia Institucional, Universidade Federal do Espírito Santo. Vitória, ES, Brasil. jesiozamboni@ gmail.com; xela_alex@ bol.com.br; carolinaroseiro@ hotmail.com 


\section{Introdução}

A vida de mulheres e homens trans - transexuais, travestis e transgêneros parece apresentar a transformação do corpo como crucial na sua produção, que pode ser realizada por meio de diversos recursos, cujo objetivo final pode residir na obtenção de um corpo que represente o pertencimento a uma perspectiva de gênero desejada, felicidade, beleza, ganhos financeiros para as pessoas trans que trabalham com sexo, saúde, bem-estar físico, psíquico e social ${ }^{1-4}$.

As estratégias de transformação dos corpos podem variar entre uso de hormônios, aplicações de silicone industrial em seios, nádegas, coxas, quadris e outras partes do corpo; pela realização de cirurgias plásticas, tais como histerectomias para retirada do útero, mastectomia para retirada das mamas, transgenitalização para mudança das genitálias, entre outros recursos cuja escolha será mediada pelas vontades pessoais e subjetividades em negociação com necessidades profissionais e condições socioeconômicas para adquiri-las $s^{1-4}$.

Nesse sentido, a vida de homens e mulheres trans, com suas singularidades e particularidades, solicita ao Estado e aos serviços públicos de saúde um tratamento diferenciado, com atendimentos especializados que compreendam suas necessidades de transformação corporal como necessidade em saúde, bem como os demais desdobramentos políticos, estéticos, sociais, econômicos e culturais de seus processos de transição no gênero como componentes de seus processos de saúde e doença ${ }^{1-5}$.

Nessa direção, ao contrário da maioria dos trabalhos sobre saúde da população trans, que vislumbrou identificar os desafios à sua promoção, diagnosticando situações-problema e propondo ações, este artigo apresentará as propostas, soluções e reivindicações apresentadas por pessoas trans aos seus atendimentos nos serviços de saúde no âmbito do Sistema Único de Saúde (SUS).

\section{Metodologia}

Foi realizada pesquisa qualitativa, na qual os dados foram coletados por meio de entrevistas semiestruturadas, gravadas em áudio digital e orientadas por um roteiro. Foi entregue a cada entrevistado uma cópia do roteiro e sugerido que escrevessem nele, se assim desejassem. Essa estratégia permitiu reduzir as limitações da entrevista, uma vez que muitos acrescentaram informações importantes que não foram narradas e outros concederam a entrevista sob a condição de não gravar, aceitando redigir sobre o roteiro. Também foi utilizado diário de campo para gravar impressões dos pesquisadores.

A amostra foi definida pelo critério de saturação, de forma que cada participante foi compondo o grupo da pesquisa por proximidade ou indicação de outro participante entrevistado, encerrando-se a coleta quando as respostas apresentavam repetições, ou seja, quando cada novx ${ }^{(f)}$ participante já não apresentava elementos novos em suas falas. Fontanella et al. ${ }^{6}$ evidenciaram que a saturação pode ocorrer entre o $11^{\circ}$ e o $15^{\circ}$ participante. Nesta pesquisa, a amostra foi composta por 15 pessoas trans ${ }^{(\mathrm{g})}$, entrevistadas no período de agosto a dezembro de 2013.

As entrevistas foram transcritas e a análise de conteúdo foi realizada, organizando-se em dois eixos: "O que esperam pessoas trans para o acesso à saúde?" e "O que esperam pessoas trans do Sistema de Saúde para a transformação de seus corpos?". Neste artigo, foram analisadas as respostas em torno do tópico "Com base em suas experiências vividas nos serviços de saúde (t) Os autores rechaçam e desafiam o gênero binário quando este é colocado compulsoriamente e impositivamente às vidas trans, compreendendo que existem vidas diversas se produzindo às margens de tais normas. Nessa direção, os pronomes e adjetivos de tratamento direcionados à população pesquisada em sua totalidade serão substituídos pela letra " $\mathrm{x}$ " como recurso gráfico. Ex: xs participantes. Assim, a letra " $x$ " poderá significar "o", "a", etc.

(g) Em consonância com a pluralidade existente nas vidas trans, ao referir-se xs participantes desta pesquisa, será utilizado o termo "pessoa trans" em um "esforço em não delimitar fronteiras entre as identidades de gênero dos participantes dessa pesquisa, respeitando não só a autoidentificação como também seus intercruzamentos nas categorias de gênero e sexualidade disponíveis" 4 (p. 2518). 
do seu município, de forma resumida, se você pudesse, o que mudaria, acrescentaria ou retiraria nos serviços de saúde que utiliza?"

As identidades de gênero e orientações sexuais apresentadas foram autodeclaradas. Os nomes descritos no texto são fictícios a fim da manutenção do sigilo dxs participantes. Todxs preencheram um Termo de Consentimento Livre e Esclarecido como requisito à participação. A pesquisa foi aprovada pelo Comitê de Ética e Pesquisa da Universidade Federal do Espírito Santo.

\section{Resultados e discussão}

\section{Caracterização da amostra}

As participações da pesquisa referem-se a um homem transexual, sete mulheres transexuais, quatro mulheres transexuais que realizaram cirurgia de redesignação sexual (mudança de sexo), duas travestis e um gay - incorporado à amostra por ter sido apresentado aos pesquisadores pelo nome social feminino, além de realizar uso de hormônios femininos. Todxs xs participantes eram residentes em municípios da região metropolitana da Grande Vitória, Estado do Espírito Santo. A idade média apresentada foi 32,6 anos, variando entre vinte e 53 anos.

Sobre as estratégias de mudança corporal, 12 participantes relataram uso de hormônios, três declararam utilização de silicone industrial em seus processos de transformação do corpo e quatro informaram cirurgias de transgenitalização (mudança de sexo).

Em relação ao mercado de trabalho, três relataram trabalhar exclusivamente com sexo, cinco com outras profissões, quatro com ambas e três com outras profissões, porém, estes últimos relataram já terem trabalhado com sexo em algum momento de suas vidas.

\section{O que esperam pessoas trans para suas mudanças corporais?}

Pelo grau de importância que as modificações corporais ganham na vida das pessoas trans, elas se constituem como elemento imanente em seus processos de saúde ou adoecimento ${ }^{1,4,7-9}$. Considerando as dificuldades no acesso aos recursos para a transformação do corpo disponíveis no Sistema Único de Saúde, somadas às limitações socioeconômicas de arcar com custos na medicina privada, visualiza-se um quadro de produção de adoecimento entre as pessoas trans, marcado por uso de hormônios sem acompanhamento médico, adoecimento mental, complicações em aplicações corporais de silicone industrial e automutilações das genitálias $1,4,7-11$.

Diante deste cenário, em 2008, o Ministério da Saúde criou o Processo Transexualizador do SUS, por meio da portaria $1707^{12}$. Isso representou um importante avanço na promoção da saúde da população trans, reconhecendo as transformações corporais como necessidade em saúde. Foram, então, incorporados na tabela de procedimentos do SUS os procedimentos transgenitalizadores autorizados no Brasil desde 1997 pelo Conselho Federal de Medicina (CFM) ${ }^{13}$. Essa conquista foi precedida por inúmeros processos de judicialização da atuação médica sobre os corpos trans e dessa demanda em saúde ${ }^{14}$, como também pelas mobilizações e articulação do movimento social com o poder público a fim de pressionar o Estado a incorporar a demanda ${ }^{15}$. Segundo Lionço ${ }^{15}$, a criação do Processo Transexualizador do SUS problematizou a atenção à saúde de pessoas transexuais como restritas ao custeio de procedimentos médico-cirúrgicos focados nas cirurgias de transgenitalização.

A portaria 1707/2008 autorizou procedimentos MTF (masculino para feminino), beneficiando mulheres transexuais com serviços de hormonioterapia, cirurgias para retirada do pomo de Adão, alongamento das cordas vocais e cirurgias de neocolpovulvoplastia (mudança de sexo MTF). Somente em 2013, com a ampliação do Processo Transexualizador do SUS a partir da portaria 2803, homens transexuais e travestis tiveram suas demandas por hormonioterapia e por procedimentos FTM (feminino para masculino) como mastectomia, histerectomia e neofaloplastia (mudança de sexo FTM) incorporados pelo SUS ${ }^{16}$.

O estado do Espírito Santo, como outros estados brasileiros, ainda não possui o processo transexualizador do SUS. Contudo, o Hospital Universitário da Universidade Federal do Espírito Santo 
realiza cirurgias de redesignação sexual desde $1998^{17,18}$, permitindo que parte da população trans capixaba possa ter acesso a esse serviço. Em janeiro de 2016, o Hospital Universitário criou uma comissão para acompanhar o processo de credenciamento do Hospital Universitário, junto com o Ministério da Saúde, para a oferta do Processo Transexualizador do SUS no Espírito Santo ${ }^{18}$.

O Quadro 1 apresenta uma sequência de relatos de pessoas trans capixabas sobre os anseios, dilemas e perspectivas apontados em relação aos serviços públicos de saúde, oferecidos para suporte de seus processos de mudanças corporais.

Quadro 1. O que esperam do SUS para as mudanças corporais?

\begin{tabular}{|c|c|}
\hline $\begin{array}{l}\text { Cassandra } \\
\text { (travesti) }\end{array}$ & $\begin{array}{l}\text { Até hoje não dão uma orientação pra travesti, pra trans que quer se hormonizar. Aqui em Vitória não, no } \\
\text { Espírito Santo não tem nenhum médico que orienta, acompanha travesti que toma hormônio, tomam vários } \\
\text { tipos de hormônio, sem saber que pode acarretar algum problema [de saúde] daqui 10, 15, } 20 \text { anos. Acho } \\
\text { importante o auxílio médico, nesse processo da hormonização. [...] } \\
\text { É importante o quanto antes a gente conseguir aprovar pelo SUS a colocação da prótese [silicone na mama]. } \\
\text { É mais barato que ter tratar o silicone [industrial] depois com os danos. Já não disponibiliza pras mulheres } \\
\text { com câncer? Até pra elas é difícil. } \\
\text { Em alguns estados já tem ambulatório LGBT pra tratar a saúde da travesti e da trans[exual]. Aqui a gente está } \\
\text { brigando [...]. }\end{array}$ \\
\hline $\begin{array}{l}\text { Ísis (mulher } \\
\text { transexual) }\end{array}$ & $\begin{array}{l}\text { [...] silicone, hormônio pra elas [mulheres trans que trabalham com sexo]. Ginecologista pra operada, } \\
\text { psiquiatra, psicólogo, isso tudo pra operada. }\end{array}$ \\
\hline $\begin{array}{l}\text { Afrodite } \\
\text { (mulher } \\
\text { transexual) }\end{array}$ & $\begin{array}{l}\text { Um ambulatório de hormonioterapia para transexuais. } \\
\text { [...] Sempre por conta própria [uso de hormônios], por não ter um ambulatório hormonal pra as transexuais } \\
\text { no Estado, que é uma lástima, que eu até coloquei aqui no questionário, não sei se vocês viram, mas eu acho } \\
\text { que o nosso Estado tá muito mal evoluído, atrasado, porque sabemos que São Paulo - tudo bem que SP é } \\
\text { grande - tem. }\end{array}$ \\
\hline $\begin{array}{l}\text { Artêmis } \\
\text { (mulher } \\
\text { transexual) }\end{array}$ & Hormonioterapia independente da cirurgia [mudança de sexo]. \\
\hline $\begin{array}{l}\text { Atenas (mulher } \\
\text { transexual) }\end{array}$ & $\begin{array}{l}\text { Sim, mas o que eu quero questionar é outra coisa. [...] cirurgia tem que ter ginecologista e cirurgião plástico } \\
\text { [...]. O que eu acho essencial é ter uma equipe multidisciplinar, com psicólogo, assistente social, ginecologista, } \\
\text { urologista. Tem que ter uma equipe. Não adianta operar, querer fazer mulher. }\end{array}$ \\
\hline $\begin{array}{l}\text { Hércules } \\
\text { (homem } \\
\text { transexual) }\end{array}$ & $\begin{array}{l}\text { Psicólogo, psiquiatria e assistente social. } \\
\text { [...] tem aquela cirurgia que tira parte do seu corpo e implanta no clitóris para fazer o pênis. E tem outra, } \\
\text { que se utiliza uma prótese e aproveita o clitóris. E quando você toma hormônio, ele aumenta. Quanto mais } \\
\text { tempo de hormônio, maior ele vai ficando e existe até uma bomba clitoriana, que você coloca dentro e faz } \\
\text { um bombamento [para ficar ereto]. Aí você ganha alguns centímetros, só que eu não sou muito a favor disso } \\
\text { porque eu conheço muitas pessoas daqui e opera quem quer. }\end{array}$ \\
\hline $\begin{array}{l}\text { Madalena } \\
\text { (mulher } \\
\text { transexual) }\end{array}$ & Um tratamento de hormônio. \\
\hline
\end{tabular}

Destacam-se, pelas falas das pessoas participantes, a cirurgia de mudança de sexo para homens transexuais, a hormonioterapia, o silicone industrial e o atendimento multiprofissional.

Em relação aos homens trans, Hércules (Quadro 1) aponta variadas estratégias, utilizadas atualmente pela medicina cirúrgica plástica, para construção de um neofalo. Demonstra preocupação com os resultados desses procedimentos a partir das experiências de pessoas conhecidas. A demora na incorporação das demandas em saúde dos homens trans ao SUS, de 2008 a 2013, foi justificada pelo caráter experimental das cirurgias de transgenitalização para esta população. Todavia, também não foram incorporados, em 2008, os demais procedimentos requisitados por essa população, que já se encontravam disponíveis no SUS para outras populações, como mastectomia, histerectomia e 
hormonioterapia com testosterona. Bento ${ }^{1}$ relata maior procura pelas cirurgias de histerectomia e mastectomia, comparada à demanda por transgenitalização. Essa situação pode se justificar pelo fato de o útero e de as mamas produzirem formas consideradas femininas ${ }^{1}$. Retirar estruturas corpóreas secundárias, como seios, por exemplo, pode tornar-se tão desejoso quanto a cirurgia de mudança de sexo, uma vez que a construção do corpo masculino, mesmo que opere em meio à lógica binária dos sexos - que produz a ideia de seres divididos, pela natureza, em pênis/masculino/homem e vagina/feminino/mulher ${ }^{1}$ —, não se resumirá à ausência ou presença do pênis, exigindo uma complexa composição. Bento ${ }^{1}$ também aponta para um recorte de gênero na produção de técnicas de intervenção médica sobre os corpos dos homens trans, no qual "parece que a ciência não tem muita pressa em criar novas tecnologias para intervir nos corpossexuados femininos, levando-me a pensar nas assimetrias de gênero na produção das tecnologias para transformar os corpos femininos" (p. 158).

Ao que parece, a invisibilização da sexualidade e da identidade de gênero das mulheres que não vivenciam incompatibilidade entre genitália e sexo atribuído no nascimento desdobram-se na invisibilização dos homens transexuais com seus gêneros, corpos, sexualidades e desejos ${ }^{1}$. Essa invisibilização também se faz presente no campo da produção científica, como evidenciou Almeida ${ }^{3}$, segundo a qual falar sobre as transformações corporais realizadas pelos homens transexuais torna-se um grande desafio, dado o incipiente número de estudos sobre transmasculinidades. Tal invisibilidade também aparece nesta pesquisa, na medida em que apenas um homem trans compôs a amostra, não por escolha dos pesquisadores, mas pelas indicações da rede na qual realizou-se a pesquisa. Além disso, ao que parece, o Espírito Santo se une aos diversos estados brasileiros que não oferecem cirurgia de redesignação sexual para essa parcela da população trans.

Outro dilema em relação à universalização dos procedimentos oferecidos pelo SUS para mudanças corporais tem sido o acesso a esses serviços condicionado a um processo de diagnóstico. Este parece tornar seletivo o acesso a essa política pública ao condicionar o acesso aos serviços oferecidos a um diagnóstico de transexualismo. Rocon et al. ${ }^{14}$ problematizam que as resoluções do CFM não contemplam as pessoas travestis, e as definições para transexualidade e travestilidades expressas pelo Código Internacional de Doenças (CID 10), sob nomes transexualismo e travestismo, diferem entre si. Os autores ${ }^{14}$ posicionamse contra a patologização das identidades trans e interpretam que a lacuna deixada pela legislação apontada por Bento ${ }^{19}$ tem sido preenchida pelas verdades estabelecidas socialmente para os gêneros.

Bento ${ }^{19}$ evidenciou que as bases para o diagnóstico mediador do acesso aos serviços transgenitalizadores no Brasil apoiam-se em estereótipos sobre "ser homem/mulher de verdade" engendrados pelo binarismo dos gêneros e pela "instituição de uma heterossexualidade compulsória e naturalizada [que] exige e regula o gênero como uma relação binária em que o termo masculino diferenciase do termo feminino [...] por meio das práticas e do desejo sexual." ${ }^{20}$ (p. 45). Assim, a equipe de profissionais envolvidos no acompanhamento e diagnóstico da população trans nos serviços de saúde estaria buscando encontrar um(a) "transexual de verdade" - que melhor reproduz na estética do corpo e nas performances de gênero o gênero binário e a heterossexualidade compulsória ${ }^{(\mathrm{h})}$. Para esse feito, Almeida e Murta ${ }^{21}$ apontam que foi elaborada uma semiologia do gênero, que vislumbraria examinar comportamentos e identidades sexuais, reafirmando a necessidade de uma compatibilidade entre anatomia e identidade de gênero. 
Aparentemente, o processo de diagnóstico pode se apresentar como uma forma de proteger xs pacientes de escolhas equivocadas sobre a realização de procedimentos irreversíveis dos quais possam se arrepender. Todavia, o diagnóstico tem tornado seletivo o acesso a serviços de saúde com potencialidade para promover e proteger a saúde da população trans de forma universal. Cassandra (Quadro 1) demonstra preocupação com os riscos à saúde da população trans envolvidos no uso de hormônios sem acompanhamento médico e nas aplicações de silicone industrial, riscos que, para a entrevistada, poderiam ser evitados com a incorporação plena e oferta universal desses recursos à população trans. A hormonioterapia aparece como necessidade nas falas de Madalena, Ísis, Artêmis e Afrodite (Quadro 1) que relatam utilizar hormônios sem acompanhamento médico, por não existir um serviço para esse cuidado demandado pelas pessoas trans. Merece destaque o fato de Cassandra, Afrodite e Artêmis (Quadro 1) apontarem para a necessidade de um ambulatório para esse serviço independente do processo transexualizador, sendo citadas experiências de outros Estados, como São Paulo, permitindo sugerir que as cirurgias de mudança de sexo não serão um desfecho unânime nas vidas atravessadas por esse programa, embora sejam importantes.

Estudos $^{4,8,7}$ permitem ainda sugerir que o diagnóstico tem contribuído para o adoecimento de parte dessa população, uma vez que, ao não conseguirem acessar os serviços de saúde necessários aos processos de mudança corporal, muitas pessoas trans são condicionadas a recorrer à hormonização sem acompanhamento médico e aplicações de silicone industrial sob risco de adoecimento ou morte ${ }^{4,7,11}$.

É preciso considerar também as diferenças culturais entre as regiões do Brasil, uma vez que Almeida e Murta relatam que "no norte/nordeste, a categoria transexual praticamente não existe. Assim, é comum que travestis procurem o programa em busca de mudanças corporais que podem abranger a modificação genital" 21 (p. 397). Os autores demonstram a importância de compreender as vidas trans entre múltiplos elementos que as cercam e as fragilidades de um diagnóstico que busca padronizar as vidas trans sob a inexistente figura $\mathrm{dx}$ "transexual de verdade". Há ainda evidências sobre "a própria patologização como fator de sofrimento e agravo à saúde" ${ }^{15}$ (p. 51). Rocon et al. ${ }^{14}$, a partir de Foucault ${ }^{22,23}$ e Bento ${ }^{1,19}$, afirmam que todo acompanhamento dxs pacientes no processo de diagnóstico é atravessado por ações de disciplinarização dos corpos trans, em uma espécie de reeducação em relação ao gênero binário.

A partir do exposto, é importante ressaltar que não se deve individualizar as consequências negativas da utilização de recursos para transformação corporal fora dos serviços de saúde, reduzindoas a escolhas inconsequentes ${ }^{4}$. A transformação do corpo, em diversas modalidades, é parte indissociável da produção de vida trans. Um elemento bastante importante nessa produção, dadas as condições de exposição a inúmeras vulnerabilidades sociais, como a perda de laços familiares e a necessidade de sobreviver, é a recorrência ao trabalho com prostituiçãa $0^{1,2,4,7}$, o qual geralmente requer modificações corporais para conseguir clientes, garantir e aumentar os ganhos financeiros $\mathbf{s}^{1,2,4,7}$. Assim, modificar o corpo se integra à produção de vida e à criação de condições para vivê-la ${ }^{4}$. Ísis (Quadro 1) reafirma os achados da literatura ao reforçar a necessidade da oferta de hormônios e silicone às pessoas transexuais e travestis que trabalham com sexo.

Duarte $^{8}$ aponta a existência de movimentos nacionais e internacionais cuja bandeira é a despatologização das identidades de gênero trans. Contudo, as discussões sobre esta temática parecem não encontrar consenso dentro dos movimentos sociais de travestis e transexuais. Bento e Pelúcio ${ }^{24}$ falam que parte da militância social enfrenta a problemática como uma concessão estratégica, por temerem o fim dos serviços oferecidos com a retirada do caráter patológico da transexualidade. Almeida e Murta $^{21}$ evidenciaram que, mesmo com a produção de avanços e consensos, a despatologização trans continua uma situação complexa. "Como garantir/ampliar o acesso de pessoas trans ao sistema, se todo ele opera majoritariamente pela lógica da doença e do transtorno e, consequentemente, da correção dos corpos ao padrão que se definiu como normal?"21 (p. 500).

Almeida e Murta ${ }^{21}$ retomam, assim, uma série de grandes desafios a serem superados para a efetivação do SUS no Brasil: o modelo biomédico hegemônico, os apelos mercadológicos à Saúde Pública e a insistente compreensão da saúde como ausência de doença. É ainda predominante o protagonismo da doença nos processos de produção de tecnologias, saberes, intervenções profissionais e investimentos públicos em saúde. Almeida e Murta ${ }^{21}$ também defendem, como uma forma de 
resistir ao modelo de atenção biomédico no processos transexualizadores, a necessidade de uma atenção multiprofissional que ofereça "o suporte técnico e ético necessário a quem desejar enfrentar os inúmeros desafios físicos, familiares, relacionais, profissionais que são comuns àquele/àquela que afirma uma identidade de transexual" (p. 401). Os autores vão ao encontro de Hércules, Ísis e Atenas (Quadro 1), que demonstram que as pessoas trans necessitam de serviços que extrapolem a lógica curativa e biomédica de atenção à saúde. Para além da necessária oferta de cirurgias e hormônios, elxs reivindicam serviços capazes de oferecer uma atenção integral em saúde, pautada na autonomia e no respeito ao processo de transição no gênero dxs pacientes, assistindo-xs com equidade.

Por fim, para Rocon et al. ${ }^{4}$, ainda que manter a patologização das identidades de gênero trans possa significar uma concessão estratégica, o SUS constitucional não condiciona o acesso aos serviços públicos de saúde à existência prévia de uma patologia instalada. Neste sentido, para que o rocesso transexualizador seja universalizado - funcionando com integralidade na atenção, equidade, participação social e respeitando a autonomia das pessoas trans sobre seus corpos e vidas -, será necessária a concretização do SUS conciliada com os valores éticos e políticos da Reforma Sanitária.

\section{O que esperam pessoas trans sobre o acesso à saúde?}

O gênero binário e a heterossexualidade compulsória operam pela linguagem ${ }^{20}$. Um exemplo clássico é a determinação do sexo/gênero de um feto por meio do recurso da ultrassonografia. Quando se declara "é um menino" ou "é uma menina", destina-se o corpo em formação à vida generificada: brinquedos, roupas, cor do quarto e uma infinidade de objetos, comportamentos, processos disciplinares e ações são atribuídas de significado a partir da divisão por sexo/gênero ${ }^{1,19,23}$. O ato de nomear, interpelando um sujeito a assumir determinado sexo/gênero, "acontece no interior de uma lógica que supõe o sexo como um dado anterior à cultura e lhe atribui um caráter imutável, a-histórico e binário" 25 (p. 15). Funcionando assim, a linguagem é produto e produtora de materialidade nas relações entre gênero, corpo e sexualidade.

O trânsito nos gêneros realizado pela população trans também acontece no campo da linguagem, tornando a modificação do nome próprio e do gênero nos pronomes de tratamento em elementos constantemente associados às transformações físicas do corpo ${ }^{4}$. Essas mudanças linguísticas, reivindicadas em dissonância com as normas hegemônicas de sexo/gênero, funcionam como recurso condicionante para o empreendimento da transformação corporal. Desse modo, a linguagem funciona como um campo de produção de vida ${ }^{25}$. Benedetti ${ }^{26}$, ao relacionar linguagem à produção do corpo trans, afirma que "o corpo das travestis é, sobretudo, uma linguagem; é no corpo e por meio dele que os significados do feminino e do masculino se concretizam e conferem à pessoa suas qualidades sociais. É no corpo que as travestis se produzem enquanto sujeitas" 26 (p. 11).

Não é dicotômica a relação entre corpo físico/biológico e linguagem/ cultura; assim, para as pessoas trans, as alterações na linguagem podem ser tão importantes quanto as modificações nas estruturas físicas do corpo ${ }^{20}$. Portanto, desconsiderar essa face do processo de trânsito no gênero pode contribuir para processos discriminatórios de desumanização e exclusão do acesso aos serviços de saúde a essa população.

Episódios de transfobia e travestifobia ${ }^{(i)}$ praticados por profissionais da saúde, nos variados estabelecimentos e níveis de atenção, configuram barreiras para o acesso à saúde pela população trans ${ }^{8}$. $O$ desrespeito ao nome social|4,7,8 
apresenta-se como uma das principais formas de discriminação presentes no cotidiano dos serviços de saúde. Como efeito, dezenas de pessoas trans resistem em buscar tratamentos de saúde por medo de sofrerem discriminação $0^{4,7,8}$. Ocorre também o abandono de tratamentos em saúde importantes, como os de HIV/AIDS ${ }^{4}$, produzindo um quadro de exclusão do acesso à saúde. Tendo em conta as condições de vulnerabilidade social que geralmente vivem as pessoas trans, essas situações de violência nos serviços de saúde podem produzir quadros de adoecimento irreversíveis e levar à morte $1,4,7,8,11$. O Quadro 2 apoia essa argumentação, uma vez que as soluções, provocações e apontamentos apresentados pelas entrevistadas, a partir de experiências na busca por serviços públicos de saúde, são atravessados pelo combate à discriminação e pela luta por respeito ao nome social.

Quadro 2. O que esperam, o que mudariam e o que fariam para melhorar o SUS?

\begin{tabular}{|c|c|}
\hline \multicolumn{2}{|r|}{ Sobre o acesso à saúde } \\
\hline Cassandra & Eu iria tornar o Sistema mais humanizado e facilitar o acesso ao segmento LGBT. \\
\hline Afrodite & Palestras e seminários sobre diversidade sexual para todos que trabalham em Unidades Básicas de Saúde e hospitais. \\
\hline Efigênia & $\begin{array}{l}\text { Tinha que ter mais orientação sobre a diversidade sexual e a diferença para ser mais respeitado sobre a identidade } \\
\text { de gênero e orientação sexual. Sobre ter respeito a todas as orientações, direito igual e poder usar o nome } \\
\text { social para todas e todos trans, feminina ou masculino, por todos os tipos de médico, enfermeiros, porteiros e } \\
\text { recepcionistas, todos que trabalham nos locais privado e público pelo SUS. }\end{array}$ \\
\hline Xena & $\begin{array}{l}\text { Que marcasse um dia para que as travestis e trans fossem atendidas. Pois quando vamos ao médico, temos que } \\
\text { falar muito rápido devido às pessoas que estão aguardando lá fora. [redigido no roteiro] }\end{array}$ \\
\hline Pandora & $\begin{array}{l}\text { Pessoas capacitadas para atender as pessoas de qualquer forma pessoas [atender todas as pessoas com } \\
\text { qualidade]. }\end{array}$ \\
\hline \multicolumn{2}{|r|}{ Pessoas trans trabalhando na saúde } \\
\hline Cassandra & $\begin{array}{l}\text { Esse é um serviço [agente comunitário de saúde] que precisa fazer, trazer pessoas que tenham a vivência. Que } \\
\text { vive isso na pele que é [quem sabe]. Não colocar alguém lá que não tenha propriedade. }\end{array}$ \\
\hline Ísis & $\begin{array}{l}\text { Não sabe nada, nada, nada sobre isso [trabalho com sexo] e tem vergonha de chegar até uma travesti [sobre } \\
\text { agentes comunitários de saúde que não são trans]. }\end{array}$ \\
\hline
\end{tabular}

As sugestões de Afrodite e Efigênia (Quadro 2) poderiam responder ações de educação permanente para os trabalhadores em saúde, uma vez que propõem a realização de palestras e seminários sobre diversidade sexual para profissionais da saúde com orientações sobre respeito às identidades de gênero trans e ao nome social. Ambas não restringem suas propostas às equipes de saúde stricto, mas compreendem todxs xs trabalhadorxs que compõem os equipamentos de saúde - das recepções e portarias aos consultórios. A discriminação nos estabelecimentos de saúde iniciamse nas recepções, com o desrespeito ao nome social e a discriminação por meio da produção de situações vexatórias por profissionais, podendo ocasionar absenteísmo; abandono de tratamentos em andamento e de consultas agendadas; e resistência na busca por serviços de saúde ${ }^{4,8,7}$. Essa situação provoca $\mathrm{o}$ ato de pensar a necessidade de compreender todxs xs trabalhadorxs que integram os estabelecimentos de saúde como profissionais da saúde, integrando-os no processo de acolhimento e cuidado por meio da gestão coletiva dos processos de trabalho.

As propostas de Afrodite e Efigênia (Quadro 2) vão de encontro aos anseios de Pandora e Cassandra (Quadro 2), que apresentam o desejo de que hajam pessoas capacitadas a respeitar as pessoas trans da mesma forma que xs demais pacientes, oferecendo um acolhimento humanizado à população LGBT e facilitando o acesso desse segmento na medida em que elimina as barreiras produzidas pelo preconceito e pela discriminação. Romano ${ }^{7}$ relatou sua bem-sucedida experiência de acolhimento de pessoas trans em um Programa de Saúde da Família, no qual profissionais passaram a respeitar as usuárias trans e estas, a ocupar e se apropriar do espaço da Unidade de Saúde. Para tanto, 
a autora apontou que o acolhimento apresenta três características: "Garantia do acesso universal, [...]. 2. Reorganização do processo de trabalho, deslocando o eixo central do médico para a equipe multiprofissional de acolhimento [...]. 3. Qualificação da relação profissional de saúde-usuário [...]"7 (p. 215).

Xena (Quadro 2) expõe o desejo de um dia reservado para atendimento da população trans, alegando a rapidez nas consultas médicas. Em sua fala, fica implícita a necessidade de um acompanhamento profissional comprometido com as necessidades específicas em saúde, além de uma organização do trabalho que promova a atenção e o cuidado integral. Esse desejo dialoga com a reinvindicação de um ambulatório para atendimento integral à saúde da população trans em todos os estados brasileiros. É importante destacar que, além da garantia de atendimento a uma parcela específica da população visando a equidade, busca-se a integralidade na atenção em saúde pela modificação nos modos de relação entre xs sujeitxs dos processos em saúde, trabalhadores e usuários.

Cassandra e Ísis (Quadro 2) destacam a necessidade de haver pessoas trans trabalhando como Agentes Comunitários de Saúde. Elas indicam que a ausência ou dificuldade no diálogo entre profissionais da saúde e pessoas trans faz com que estas não recebam os cuidados necessários para, por exemplo, trabalharem com sexo em segurança - por meio de informações sobre prevenção e cuidados, bem como fornecimento de insumos (camisinhas e géis lubrificantes). Rocon et al. ${ }^{4}$ apontam que a inabilidade de profissionais da saúde em realizarem educação em saúde com a população trans pode estar contribuindo para o adoecimento dessa população.

\section{Considerações finais}

Entre xs participantes mulheres transexuais e travestis, o implante de prótese mamária, a hormonioterapia e os cuidados integrais e multiprofissionais parecem destacar-se em relação às cirurgias de redesignação sexual. Não se afirma que essa cirurgia não seja uma questão de importância entre mulheres transexuais; contudo, o dado corrobora com estudos ${ }^{1,3,4,19-21}$ que apontam que a busca pela mudança da genitália não é unânime entre pessoas transexuais. Logo, os protocolos de atendimento à saúde trans não devem compreender a redesignação sexual como o único desfecho nos processos de transição no gênero e, nessa direção, compreende-se a inexistência da figura de um transexual verdadeiro universal, modelo de normalização por meio do qual se afirma que todas as pessoas trans que buscam serviços do processo transexualizador devem desejar eliminar suas genitálias.

O participante homem transexual aponta as dificuldades em alcançar bons resultados nas cirurgias de neofaloplastia como um desmotivador em buscar por esse procedimento, fato apontado pela literatura ${ }^{1}$ como resultado da desigualdade na produção de tecnologias para intervenção nos corpos de homens trans. O participante também indica o cuidado multiprofissional como uma importante intervenção em direção à produção da saúde de homens trans.

São apontadas soluções que reforçam a necessidade de formação continuada pautada na promoção da humanização, da dignidade e do respeito ao nome social e às identidades de gênero para todxs xs trabalhadorxs da saúde envolvidxs no itinerário pela busca por atendimento em saúde. Essas proposições reiteram que a discriminação, a dificuldade de diálogo entre profissionais da saúde e usuárixs trans e o desrespeito ao nome social se apresentam como obstáculos ao acesso de pessoas trans aos serviços de saúde, sendo elementos responsáveis pelo adoecimento dessa população na medida em que a priva dos cuidados e da proteção em saúde.

Por fim, as soluções, indicações e provocações elencadas pelas falas apontam que um modelo de atenção à saúde biomédico e curativista não será capaz de responder às demandas em saúde da população trans. Nessa direção, as entrevistas reiteram a resistência construtora do Sistema Único de Saúde, na medida em que suas demandas em saúde requerem um sistema de saúde público, universal, integral, com justiça e participação social ${ }^{4}$. 


\section{Colaboradores}

Pablo Cardozo Rocon, Francis Sodré, Jésio Zamboni, Alexsandro Rodrigues e Maria Carolina Fonseca Barbosa Roseiro participaram em todas as fases envolvidas na produção do artigo e aprovaram a versão final apresentada.

\section{Referências}

1. Bento B. A (re)invenção do corpo: sexualidade e gênero na experiência transexual. Rio de Janeiro: Garamond; 2006.

2. Pelúcio L. Toda quebrada na plástica: corporalidade e construção de gênero entre travestis paulistas. Rev Antropol Soc. 2005; 6(1-2):97-112.

3. Almeida G. 'Homens trans': novos matizes na aquarela das masculinidades? Rev Estud Fem. 2012; 20(2):513-23.

4. Rocon PC, Rodrigues A, Zamboni J, Pedrini MP. Dificuldades vividas por pessoas trans no acesso ao Sistema Único de Saúde. Cienc Saude Colet. 2016; 21(8):2517-25.

5. Mello L, Perilo M, De Braz CA, Pedrosa C. Políticas de saúde para lésbicas, gays, bissexuais, travestis e transexuais no Brasil: em busca de universalidade, integralidade e equidade. Sex Salud Soc. 2011; 9:7-28.

6. Fontanella BFB, Luchesi BM, Saidel MGB, Ricas J, Turato ER, Melo DG. Amostragem em pesquisas qualitativas: proposta de procedimentos para constatar saturação teórica. Cad Saude Publica. 2011; 27(2):389-94

7. Romano VF. As travestis no programa saúde da família da Lapa. Saude Soc. 2008; 17(2):211-9.

8. Duarte MJO. Diversidade sexual, políticas públicas e direitos humanos: saúde e cidadania LGBT em cena. Temporalis. 2014; 1(27):77-98.

9. Arán M, Zaidhaft S, Daniela M. Transexualidade: corpo, subjetividade e saúde coletiva. Psicol Soc. 2008; 20(1):70-9.

10. Conselho Federal de Medicina (BR). Resolução n. 1.955, de 3 de setembro de 2010. Dispõe sobre a cirurgia de transgenitalismo e revoga a Resolução CFM n. 1.652, de 2 de dezembro de 2002. Diário Oficial União 3 set. 2010.

11. Ministério da Saúde (BR). Secretaria de Gestão Estratégica e Participativa. Departamento de Apoio à Gestão Participativa. Política Nacional de Saúde Integral de Lésbicas, Gays, Bissexuais, Travestis e Transexuais. Brasília: Ministério da Saúde, 2013.

12. Ministério da Saúde (BR). Portaria n. 1.707/GM de 18 de agosto de 2008. Institui, no âmbito do Sistema Único de Saúde (SUS), o Processo Transexualizador, a ser implantado nas unidades federadas, respeitadas as competências das três esferas de gestão. Diário Oficial União 18 Ago. 2008.

13. Conselho Federal de Medicina (BR). Resolução n. 1.482, de 19 de setembro de 1997. Autoriza a título experimental, a realização de cirurgia de transgenitalização do tipo neocolpovulvoplastia, neofaloplastia e ou procedimentos complementares sobre gônadas e caracteres sexuais secundários com o tratamento dos casos de transexualismo. Diário Oficial União 19 set. 1997.

14. Rocon PC, Sodré F, Rodrigues A. Regulamentação da vida no processo transexualizador brasileiro: uma análise sobre a política pública. Rev Katál. 2016; 19(2):260-9.

15. Lionço T. Atenção integral à saúde e diversidade sexual no processo transexualizador do SUS. Physis. 2009; 19(1):43-63.

16. Ministério da Saúde (BR). Portaria n. 2.803/GM de de 19 de novembro de 2013.. Redefine e amplia o Processo Transexualizador no Sistema Único de Saúde (SUS). Diário Oficial União 19 Nov. 2013. 
17. Marchioni $\mathrm{H}$. Ufes possui técnica inédita no mundo para cirurgia de mudança de sexo [internet]. 2013 [citado 05 Jun 2016]. Disponível em: http://www.ufes.br/conteudo/ufespossui-t\% C3\% A9cnica-in\% C3\% A9dita-no-mundo-para-cirurgia-de-mudan\% C3\% A7ade-sexo.

18. Medina J, Marinho T. Ufes apresenta comissão para a implementação de ambulatório trans no Hucam [internet]. 2013 [citado 05 Jun 2016]. Disponível em: http://www.ufes. br/conteudo/ufes-possui-t\% C3\% A9cnica-in\% C3\% A9dita-no-mundo-para-cirurgia-demudan \% C3\% A7a-de-sexo.

19. Bento B. O que é transexualidade. São Paulo: Brasiliense; 2008.

20. Butler J. Problemas de gênero: feminismo e subversão da identidade. Rio de Janeiro: Civilização Brasileira; 2014.

21. Almeida G, Murta D. Reflexões sobre a possibilidade da despatologização da transexualidade e a necessidade da assistência integral à saúde de transexuais no Brasil. Sex Salud Soc. 2013; 14:380-407.

22. Foucault M. Em defesa da sociedade: curso no Collège de France (1975-1976). 4a ed. São Paulo: Martins Fontes; 1999.

23. Foucault M. História da sexualidade I: a vontade de saber. 23 a ed. São Paulo: Graal; 2013.

24. Bento B, Pelúcio L. Despatologização do gênero: a politização das identidades abjetas. Estud Fem. 2012; 20(2):559-68.

25. Louro GL. Um corpo estranho: ensaios sobre sexualidade e teoria queer. Belo Horizonte: Autêntica; 2004.

26. Benendetti MR. Toda feita: o corpo e o gênero das travestis. Rio de Janeiro: Garamond; 2005.

Rocon PC, Sodré F, Zamboni J, Rodrigues A, Roseiro MCFB. ¿Qué esperan las personas trans del Sistema Brasileño de Salud?. Interface (Botucatu). 2018; 22(64):43-53.

Este articulo discute las críticas y sugerencias presentadas por personas trans para la garantía de su acceso y de la promoción de acciones para el cuidado integral de su salud en el Sistema Brasileño de Salud (SUS). Se realizaron entrevistas semi-estructuradas, grabadas en audio, transcritas y se realizó análisis de contenido. Se señaló la formación continuada para trabajadores de la salud con el objetivo de revertir la realidad de discriminación, falta de respeto al nombre social y dificultad de diálogo entre profesionales y usuarios trans, condiciones que limitan el acceso a la salud. Se consideró la necesidad de universalizar la hormonoterapia y el implante de silicona y la reivindicación de atención multi-profesional en la salud trans como formas de asegurar el cuidado y la seguridad necesarios para los procesos de transformación del cuerpo

Palabras clave: Personas transgénero. Acceso. Saúde. Cuerpo. Sistema Brasileño de Salud. 
